\title{
Design And Analysis of An Automotive Engine Shaft With Functionally Graded Material To Get An Optimum Performance
}

Saeed Ahmed ( $\sim$ drsaeedasiri3@gmail.com )

Faculty of Engineering, King AbdulAziz University

\section{Original Article}

Keywords: Automotive engine shaft, Pinion, Differential, Shaft, Functionally Graded Materials, Optimizations and Fatigue Fracture.

Posted Date: November 1st, 2021

DOl: https://doi.org/10.21203/rs.3.rs-955218/v1

License: (c) (1) This work is licensed under a Creative Commons Attribution 4.0 International License.

Read Full License 


\section{Abstract}

Engine Shafts are a very critical component of Automotive and Aerospace. Their basic purpose is to transmit power by rotation. They suppose various parts like gears and pulleys, and they are supported by bearings, which reside in the rigid machine housing. In their operation the shafts rotate and hence they are subjected to Torsion and Bending moment. Hence, it is critical for us to choose the best material and the surface treatment process to provide optimum performance for the shaft. The primary aspects to keep into consideration while choosing a material pertaining to surface selection are Wear Resistance and Corrosion resistance. It has been shown how the selection of shaft material affects these two factors. The shafts of 3 types of materials have been discussed in the paper, a homogeneous one, a composite material and FGM. The best material considered is FGM for the optimum operation of automotive engine shaft.

\section{Introduction}

This journal article focuses on selecting the best material and the surface treatment process for an engine shaft. The design for shafts is always made circular, the reason for that is because of the uniform stress distribution in the shaft along the radius, they could be either solid or hollow. In the cases where corrosion poses a serious threat to the durability of the shaft, the material most likely to withstand the longest is Stainless Steel. The two grades of Stainless steel commonly used for making linear shafts are 440C Stainless Steel and 316 Stainless Steel. (MiSUMi Mech Lab, 2021). The surface treatment processes that endow us with the best results, the two choices are Hard Chrome Plating, it provides excellent prevention to wear resistance and Low temperature Black Chrome process gives shaft the tendency to endure corrosion resistance to the fullest. The material selection criteria for an engine shaft totally depends on application. Typical application might be (but not limited to) a prime mover (engine, steam or gas turbine, electric motor, etc.) to a gearbox, compound, or generator for example. While opting for a shaft's material there are some set parameters that need to be considered such as the strength factor, element of toughness, the stiffness of shaft and the ability of the shaft to go through the variety of heat treatment processes it offers. Pertaining to (Radhi, 2018). Although, it is possible to comb some common properties that must be present in the material of which the shaft is being made, they are:

- The opted material must have a good strength

- It should be easy to be machined, so that the process of manufacturing does not require much hustle.

- Possession of good heat treatment properties is mandatory so that the shaft can withstand arduous working conditions.

In normal working the material opted for the manufacture of shafts is steel or any alloy or steel or nickel. It provides a pretty good strength and can withstand working conditions to a good extent. It available at an affordable cost, hence its preferred over a range of expensive materials. 
A functioning graded material (FGM) is a kind of amalgamated form obtained from the combination of two or more types of materials. In the combination of properties of an FGM are projected upon as a compositional gradient onto the other, hence it displays varying properties under different conditions. Given below is the production method, listed sequentially for Functionally Graded Materials.

\section{Methodology}

The study involves the selection of the perfect material that will prevent failure to the greatest extent. To be deciding that it is important to know first about the relevant failures that occur in a life of an engine shaft.

When accounting for the failures that a shaft might undergo, it must be examined which the type of loads that act on it during its operation. The most common type of load is rotational that results in torsion and bending of the shaft that might cause it to lose its rigidity and hence the system could fail. Some other loads that act on the shaft might be due to the place of operation. For example, in systems that work underwater, the shaft might undergo corrosion due to the presence and effect of water underneath. Hence, it is compulsory to go prepared for these unprecedented circumstances.

Fig. 1 shows the example of a cylinder and how different forces act on it to cause deformation. This study focuses on doing the modal and the harmonic analysis of the engine shaft that is made, and the choice of materials are, a homogenous selection of stainless steel (440C and $\mathbf{3 1 6}$ ), a composite material (Carbon fiber Epoxy) and a Functionally Graded Material. Fatigue failure is brought about by repetitive cycles of loading, it is a surprising fact but the forces that would cause plastic deformation is greater than the ones leading to fatigue failure. The two important aspects to consider while testing for a part's strength that gives us an indication of how much endurance and reliability it confides to, can be examined by its corrosion resistant properties and the ease by which it resists erosion Let us discuss the fatigue planes and the mechanism with which fatigue failure causes our engine shaft to fail. In the unlikely case of a fatigue failure, it is mandatory to critically examine the break planes to come up to a preventive technique. Given below in Figure 2, is the engine shaft made in SolidWorks 18 that will be used to examine the best material for the component.

As it withstands is that of torsion. The goal is to have a shaft strong enough that would have enough torsional strength in it to withstand the torque acting on it (Gebresilassie, 2012).

\section{Results}

In this study it required to perform the modal analysis, harmonic analysis and compare the total deformation of the three engine shafts using ANSYS Workbench 2021. The analysis to be done on the shafts are the harmonic analysis to and response spectrum to examine the effect of the shaft under the action of the loading that gives rise to certain frequencies which are distinct to the type and magnitude of the force that acts. That frequency is called the natural frequency and when the natural frequency 
matches with the frequency of vibration resonance occurs which might be the root cause of the propagation of cracks within the surface. Along with this, Harmonic analysis is the study of linear actions of groups on vector spaces. Any action of a group on a set gives rise to actions on vector spaces of functions defined on that set. Group actions, in turn, are important because many mathematical structures can be analyzed by studying the group of transformations which preserve that structure. Projective actions of groups are closely related to linear ones and play a central role in quantum mechanics; there is a close relationship between elementary particles and the ways that these representations interact.

\subsection{Engine Shaft (AISI 316 Stainless steel)}

ASS parent alloy, 304, has considerably good resistance to a wide range of atmospheric environments and many corrosive media but when certain amount of Mo is added in base 304 alloy then the resultant alloy becomes excellent material to be used in highly corrosive environment (Pitting and crevice corrosion) (Islam M. El-Galy, 2019). This alloy with increased Resistance to pitting and crevice corrosion is called 316 SS. Some important characteristics of the chosen material for engine are:

Stainless steel is a good choice for selection because of its immune protection against corrosion, its high strength, and the ability to resist fracture. These make it a very good choice for working in harsh conditions. Given below in Table 1. the set of properties taken from ANSYS of the material used are listed.

Table 1 Properties for Stainless steel 316 (Azom, 2021)

\begin{tabular}{|ll|}
\hline Stainless Steel 316 & \\
\hline Property & Value \\
\hline Density & $8000 \mathrm{~kg} / \mathrm{m}^{3}$ \\
\hline Atomic Volume (average) & $0.007 \mathrm{~m}^{3} / \mathrm{kmol}$ \\
\hline Bulk Modulus & $145 \mathrm{GPa}$ \\
\hline Elastic Limit & $250 \mathrm{MPa}$ \\
\hline Endurance Limit & $270 \mathrm{MPa}$ \\
\hline Fracture Toughness & $200 \mathrm{MPa} \cdot \mathrm{m}^{1 / 2}$ \\
\hline Tensile Strength & $500 \mathrm{MPa}$ \\
\hline Thermal Conductivity & $15 \mathrm{~W} / \mathrm{m} . \mathrm{K}$ \\
\hline Resistivity & $7510^{-8} \mathrm{ohm}{ }^{\star} \mathrm{m}$ \\
\hline
\end{tabular}

The part made in SolidWorks is shown in Figure 3 below: - 
Table 2 represents the variation of frequency for every mode shape as the engine shaft is subjected to vibrations due to load. The given natural frequencies correspond to the behavior of the object when it is subjected to loadings and intensities which then lead to failure.

Table 2 frequencies for mode shapes (SS-316)

\begin{tabular}{|ll|}
\hline Mode & Frequency $(\mathrm{Hz})$ \\
\hline 1 & 1634.3 \\
\hline 2 & 1697.1 \\
\hline 3 & 2805.8 \\
4 & 4718.3 \\
\hline 5 & 4823.1 \\
\hline 6 & 7807.6 \\
\hline 7 & 8800.2 \\
\hline 8 & 9011.6 \\
\hline 9 & 11165 \\
\hline 10 & 13878 \\
\hline
\end{tabular}

In Figure 4 the graphical representation of frequency obtained from the mode shapes in ANSYS is shown. The maximum natural frequency for a mode shape tells us about the highest vibrational intensity that the shaft will be subjected to during its operation. As opposed to the minimum, both parameters along with the no. of cycles play an important role in determining the total deformation that occurs. Later, the maximum frequencies, amplitude, and the total deflection for the three cases will be compared to choose the best material for the engine shaft.

Some insights about total deformation in this scenario are:

Deformation generally stands for the case when an exerted force causes a change in a body's nodal displacement, and it loses its shape and rigidity. From ANSYS, the results of total deformation in the shaft have been computed and attached below.

The Figure 5 above explains the Deformation that is the variation or change in the object's nodal displacement. The deformation occurs when the displacement of the nodes is beyond a certain benchmark and then the object adopts a shape different from the original. It is a result of successive loadings that insinuate that whether a part or a certain material is ready or enough for a part or not

Harmonic response analysis in ANSYS (as well as in any other FEA program) can be used to obtain steady-state response of a model subjected to a load that changes harmonically (sinusoidally) in time. Such load has specific amplitude and frequency at which it acts. The load causes forced vibrations. The 
calculated response is a function of frequency. These simulations can only be linear and are often performed after eigenfrequency analysis since extracted natural frequencies can be used as a harmonic load frequency to obtain actual stress and displacement in such conditions (eigenfrequency analysis only gives mode shapes with arbitrary magnitudes instead of actual displacement values). The frequency response for engine shaft- SS 316 is shown in Fig. 6.

\subsection{Engine Shaft (Carbon Fiber)}

Carbon fiber is one of the allotropic crystalline forms of the element. Among the other forms are diamond, graphite and bucky balls. Carbon fiber is essentially a one-dimensional form, as diamonds and buckyballs are three dimensional, and graphite a 2-dimensional form. Carbon fiber can be visualized as a helix of atoms around a hollow center. The fiber winds around with each layer translated up by one atom from the layer below. The fiber grows along the central core and expands chemically. With this crystalline structure an incredibly strong fiber is achieved. Carbon fiber is the material that consists of various strands of carbon that are bonded tightly together, and the result is a stiff, lightweight, and strong material which can be employed for various constructional purposes. It is widely used in manufacture and our studies revolves around finding the epitome of optimized working for our engine shaft.

Table 3 Properties of Carbon Fiber (Azom, 2021)

\begin{tabular}{ll} 
Carbon Fiber & \\
\hline Property & Value \\
\hline Density & $2000 \mathrm{~kg} / \mathrm{m}^{3}$ \\
\hline Atomic Volume (average) & $0.002 \mathrm{~m}^{3} / \mathrm{kmol}$ \\
\hline Bulk Modulus & $228 \mathrm{GPa}$ \\
\hline Elastic Limit & $200 \mathrm{MPa}$ \\
\hline Endurance Limit & Not specified \\
\hline Fracture Toughness & $50 \mathrm{MPa} \cdot \mathrm{m}^{1 / 2}$ \\
\hline Tensile Strength & $3.5 \mathrm{GPa}$ \\
\hline Thermal Conductivity & $21 \mathrm{~W} / \mathrm{m} \cdot \mathrm{K}$ \\
\hline Resistivity & $88410^{-8} \mathrm{ohm}{ }^{\star} \mathrm{m}$
\end{tabular}

Table 3 shows the different parameters on which the standard and performance of the engine shaft depends. Hence it will be examined whether if carbon fiber is a good choice or not for our development of an engine shaft. In the pursuit, different tests are conducted on the three models made and the 
conclusions have been derived later on in the document. Carbon fiber is known for its stiff nature, it is also compared at the end to provide with a good and sound reasoning for making engine shafts on a commercial scale.

In Figure 7 the $3 \mathrm{~d}$-model of the shaft made in solid works with Carbon fiber applied on it is shown. Firstly, the various natural frequencies that arise when the engine shaft is loaded are discussed.

The variation for carbon fiber can be examined in Fig. 8. A comparative analysis of Figures 4,8 and 12 tells us that the maximum natural frequency of vibration is more in the case of carbon fiber as compared to Stainless steel-316. The increasing values of frequencies tell us that the increasing intensities of vibration put the engine shaft under successive vibrations. A certain span that is distinct for every material being used comes when the frequencies result in shaft failure.

Table 4 Natural Frequencies of Carbon fiber

\begin{tabular}{|ll|}
\hline Mode & Frequency $(\mathrm{Hz})$ \\
\hline 1 & 1182.1 \\
\hline 2 & 1214.6 \\
\hline 3 & 1975.3 \\
\hline 4 & 3419.6 \\
\hline 5 & 3428.2 \\
\hline 6 & 5640.7 \\
\hline 7 & 6365.7 \\
\hline 8 & 6393.2 \\
\hline 9 & 7847 \\
\hline 10 & 9884.2 \\
\hline
\end{tabular}

Table 4. shows us the natural frequencies for carbon fiber. The report focuses on preventing that scenario and proposes a solution by comparing the performance of engine shafts of a homogenous material, a composite, and a functionally graded material.

The total deformation in the carbon fiber is shown in Fig. 9. At low loads, most materials deform elastically. Many people mechanical deformation to refer to this sort of elastic deformation. Deformation is often described as strain. In the oilfield, it can be described as the pressure and resultant change in the rock that is hydraulically fractured.

Figure 10 shows the frequency response for carbon fiber obtained from ANSYS. The behavior of the shafts pertaining to steady state responses will be discussed below. It involves the evaluation of an objects performance when it is subjected to loadings. 


\subsection{Engine Shaft (Ti-6Al-4V) FGM}

The most used alloy is 6al4v (Grade 5) Titanium (Radhi, 2018). This alloy is made of about $6 \%$ aluminum, $4 \%$ Vanadium, a tiny number of miscellaneous elements, and the rest Titanium. This has a combination of excellent strength and corrosion resistance. It is heat treatable as well.

Titanium ( $\mathrm{Ti}$ ) has two primary advantages over steel: It is lighter than steel. Iron (Fe) has a density of 7.8 grams $/ \mathrm{cm}^{\wedge} 3$, but Ti has a density of $4.5 \mathrm{grams} / \mathrm{cm}^{\wedge} 3$. That gives $\mathrm{Ti}$ as much higher specific strength, which is defined as the strength divided by the density. Contrary to popular mythology and marketing, $\mathrm{Ti}$ is not stronger than steel, in general. There are some alloys of steel that are not as strong as some heat treatments of many materials but there is no Ti-6Al-4V that has the yield strength that high strength steels like AISI 4340 and $300 \mathrm{M}$ can have. It is all a question of heat treatments. But in any event, $\mathrm{Ti}$ alloys have a higher specific strength than any ferrous alloys.

Table 5 Properties of Ti-6Al-4V

\begin{tabular}{|ll|}
\hline FGM (Ti-6Al-4V) & \\
\hline Property & Value \\
\hline Density & $4500 \mathrm{~kg} / \mathrm{m}^{3}$ \\
\hline Atomic Volume (average) & $0.011 \mathrm{~m}^{3} / \mathrm{kmol}$ \\
\hline Bulk Modulus & $130 \mathrm{GPa}$ \\
\hline Elastic Limit & $850 \mathrm{MPa}$ \\
\hline Endurance Limit & 550 \\
\hline Fracture Toughness & $95 \mathrm{MPa} \cdot \mathrm{m}^{1 / 2}$ \\
\hline Tensile Strength & $1000 \mathrm{MPa}$ \\
\hline Thermal Conductivity & $7.2 \mathrm{~W} / \mathrm{m} . \mathrm{K}$ \\
\hline Resistivity & $16910^{-8}$ ohmm \\
\hline
\end{tabular}

Table 5 shows the properties of the FGM chosen. Composites are by and large homogenous through their material volume when managing a two-segment framework, and their properties are then additionally uniform through that material volume (in a specific course). FGMs could likewise be constrained by the advancement of various material stages or designs (consider varieties in precipitation solidifying), if it is done in a controlled matter through the volume by means of the creation technique (Charnont Moolwana, 2012). Ti alloys can be used at much higher temperatures than steel alloys. Ferrous alloys rapidly lose strength as the temperature goes up beyond about $300 \mathrm{C}$, but Titanium alloys maintain good strength to over 500C. 3D printing is a pleasant illustration of how practical material properties can be characterized through a material construction by variety in cell structure (going from a low to high filling level in 
smoother progress) and changing the solidness or directional properties. In Fig. 11 the 3-d model made in solid works is and the FGM applied to it.

Given below in Table 6 is the tabular representation of the increasing values of natural frequencies pertaining to the mode shapes resulted.

Table 6 Natural Frequencies for FGM

\begin{tabular}{|ll|}
\hline Mode & Frequency $(\mathrm{Hz})$ \\
\hline 1 & 1657.9 \\
\hline 2 & 1728.5 \\
\hline 3 & 2745.1 \\
\hline 4 & 4818.9 \\
\hline 5 & 4950.3 \\
\hline 6 & 7986.8 \\
\hline 7 & 8983.7 \\
\hline 8 & 9223.4 \\
\hline 9 & 11012 \\
\hline 10 & 14118 \\
\hline
\end{tabular}

Given below in Figure 12 is the variation of natural frequency in our third case of interest.

Figure 12 shows the frequency variation for the FGM engine shaft obtained from ANSYS. The results obtained from ANSYS for total deformation have a colored representation of the concentration of stresses in the body. It gives insights onto the most vulnerable portion of the component. Some important Key Performance indicators will be elicited that lead to various shaft failures. As most of the shafts have a circular cross-section.

In that case, stress concentration is mostly around the edges of the diameters and hence there is a fatigue failure close to the circumferential boundary of the shaft (Charnont Moolwana, 2012). Figure 13 represents the total deformation for the engine shaft made from Functionally Graded Material (FGM).

In Figure 13, the total deformation in the engine shaft of FGM can be examined. It is obvious that the stress concentration is lesser when compared to the above two cases discussed.

Figure 14 depicts the frequency response for the engine shaft of FGM, obtained from ANSYS.

\section{Comparison Of The Three Materials}


As the end goal of our study is to examine the behavior of three types of materials discussed and to select the best one for the shaft.

The gist of it is that two of the most important factors on which the shaft material is dependent upon are:

- High Strength

- Machinability

- Stiffness

Now the behavior of SS-316, Carbon Fiber and Ti-6Al-4V a FGM will be alluded to see how they vary when they are being used as an engine shaft's material.

When it comes to machinability, which is the ability of a material to be machined, its ease to be cut and processed into the desired result, stainless steel has a higher machinability than carbon fiber and Ti-6Al$4 \mathrm{~V}$. That means, when in the manufacturing conditions, a comparison using Stainless steel, will give us an edge on the other picks. Whereas, when the strengths of the three materials are compared, due to strong bonding between Aluminum and Vanadium atoms, its heat of reaction is the highest and the material possess formidable strength, so for a higher strength a shaft made of the FGM Ti-6Al-4V is the best pick. Finally, when a comparison of the stiffness of the three materials (Liu, 2011). The FGM Ti-6Al$4 \mathrm{~V}$ Is the stiffest of all of them. That enlightens us with some important deductions about its role in manufacturing engine shafts.

Fig 15. gives an overall comparison tells us that Ti-6Al-4V and stainless steel are the two better choices to be opted for both with their own qualities and perseverance of mechanical properties. Normally engine shafts are manufactured using Stainless steel, steel alloys and Nickel alloys but in cases where high stiffness is required, it is possible to use a shaft made of an FGM. Table 7 gives the comparison of stiffness for all 3 types of materials.

Table 7 Effect of temperature on Stiffness 


\begin{tabular}{|llll|}
\hline Temperature Celsius & Carbon Fiber (GPa) & Stainless Steel 316 (GPa) & Ti-4Al-6V (GPa) \\
\hline 10 & 24.45 & 15.45 & 32.45 \\
\hline 20 & 23.62 & 12.34 & 31.09 \\
\hline 30 & 23.11 & 10.3 & 31.32 \\
\hline 50 & 22.39 & 8.98 & 30.89 \\
\hline 60 & 20.12 & 5.65 & 27.34 \\
\hline 80 & 18.9 & 3.09 & 24.09 \\
\hline 110 & 15.81 & 2.89 & 23.1 \\
\hline 140 & 12.09 & 1.56 & 20.98 \\
\hline 160 & 6.8 & 0.9 & 15.09 \\
\hline 200 & 1.61 & 0.75 & 13.45 \\
\hline 260 & 0.89 & 0.32 & 12.98 \\
\hline
\end{tabular}

\section{Frequency variation- Response Spectrum}

The comparison of all three frequency results obtained for the three shafts indicate the natural frequencies of vibration for them. A lower value of resonance frequency indicates that the vibrations are of a lesser magnitude and hence it indicates a comparative greater immunity to fatigue failure. In our case the least value was detected for FGM then SS-316 and then Carbon Fiber. The frequency response spectrum for FGM indicates a stabler response because of the flattened curvature. Hence it can be deduced that FGM shaft is prone resistant to fatigue failure more than other two engine shafts. Fig 16 shows the comparison of stiffness of materials shows as a graph.

\section{Conclusions And Recommendations}

In conclusion it is elicited as per the findings of the analyses performed and the behavior of the engine shafts under their effect. The various possibilities of material selection for an Engine Shaft for an Automotive are discussed. The three picks are a homogeneous material, a composite, and a Functionally Graded material. The engine shaft was made in SolidWorks and then Modal and Harmonic analysis are applied to the parts to notice their behavior in the operating conditions. The end goal is to ensure the proper functioning of the shaft, and to increase the life of the component. Mentioned below are some common shaft failures and their preventive techniques. The fatigue crack normally initiates because of the object under examination going through successive loadings and cycles until it falls a prey to failure. It can be prevented such that proper preheating during welding. Since numerous machine components experience a high temperature through their thickness, it is important to plan the material so warm bowing is limited. It may be likewise wished to plan to coordinate with an in-plane CTE or modulus. By making an FGM as a symmetric composite whose fiber volume division shifts through the thickness, it 
can be achieved following these plan undertakings. In essence, as the properties of functionally graded materials change with different dimensions, they play an important role when a heavy stiffness component is being produced. Their specific ability enables them to acclimate with different conditions in which homogeneous materials fall vulnerable to wear and corrosion.

\section{References}

1. Charnont Moolwana, Samroeng Netpu (2012) 'Failure Analysis of a Two High Gearbox Shaft', Social and Behavioral Sciences Symposium, 4th International Science, Social Science, Engineering and Energy Conference 2012 (I-SEEC 2012)

2. Sergie Sokolov, Anton Zhilenkov and Sergie Chernye (2017) 'Assessment of the impact of the destabilizing factors in the main Engine Shaft of the Adaptive Speed Controller' $6^{\text {th }}$ International Conference on Smart Computing and Communications

3. Asmamaw Gebresilassie (2012) 'Design and analysis of Composite Drive Shaft for Rear-Wheel Drive Engine'International Journal of Scientific \& Engineering Research

4. Xiao lei Xu *, Zhiwei Yu, Hong Xin Ding (2006) 'Failure analysis of a diesel engine gearshaft'Electromechanics and Material Engineering College, Dalian Maritime University, Dalian 116026, PR China

5. H. Bayrakceken (2006) 'Failure analysis of an automobile differential pinion shaft'Afyon Kocatepe University, Technical Education Faculty, 03200 Afyon, Turkey

6. Dieter Scholz, Ravinka Serasinghe, Ingo Stack, Craig Lawson (2013) 'FUEL CONSUMPTION DUE TO SHAFT POWER OFF-TAKES FROM THE ENGINE'

7. Sergei Sokolov a , Anton Zhilenkovb , Sergei Chernyia, Anatoliy Nyrkov (2018) IImpact of Destabilizing Factors in the Main Engine Shaft of the Adaptive Speed Controller'International Conference on Computational Intelligence and Data Science

8. R. Gordon Kirk, Alan A. Korn Hauser, John Sterling and Ali Al Saeed (2009) 'Journal of Vibration and Control'Sage Publications.

9. Nabaa S. Radhi (2018) 'A Review for Functionally Gradient Materials Processes and Useful Application'Materials College engineering, University of Babylon-Hila-Iraq.

10. Liu, J., Zhou, Z., Ma, L., Xiong, J., \& Wu, L. (2011). Temperature effects on the strength and crushing behavior of carbon fiber composite truss sandwich cores. Composites Part B: Engineering, 42(7), 1860-1866.

\section{Figures}




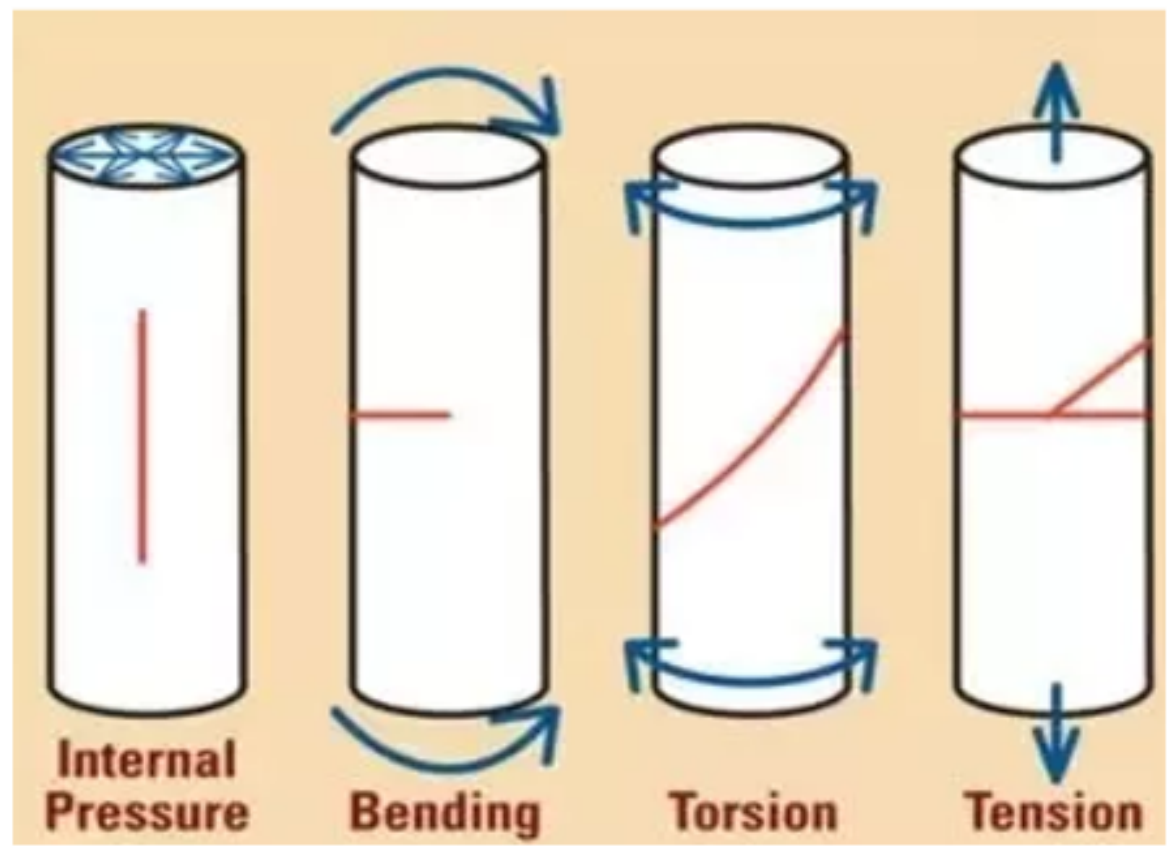

Figure 1

Fracture planes caused by general fatigue forces (Gebresilassie, 2012) 
Figure 2

Engine Shaft of an Automotive

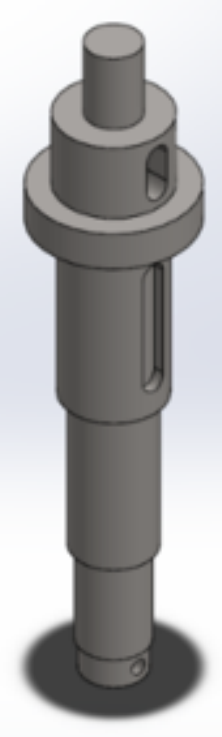

Figure 3

Stainless steel 316 (applied)

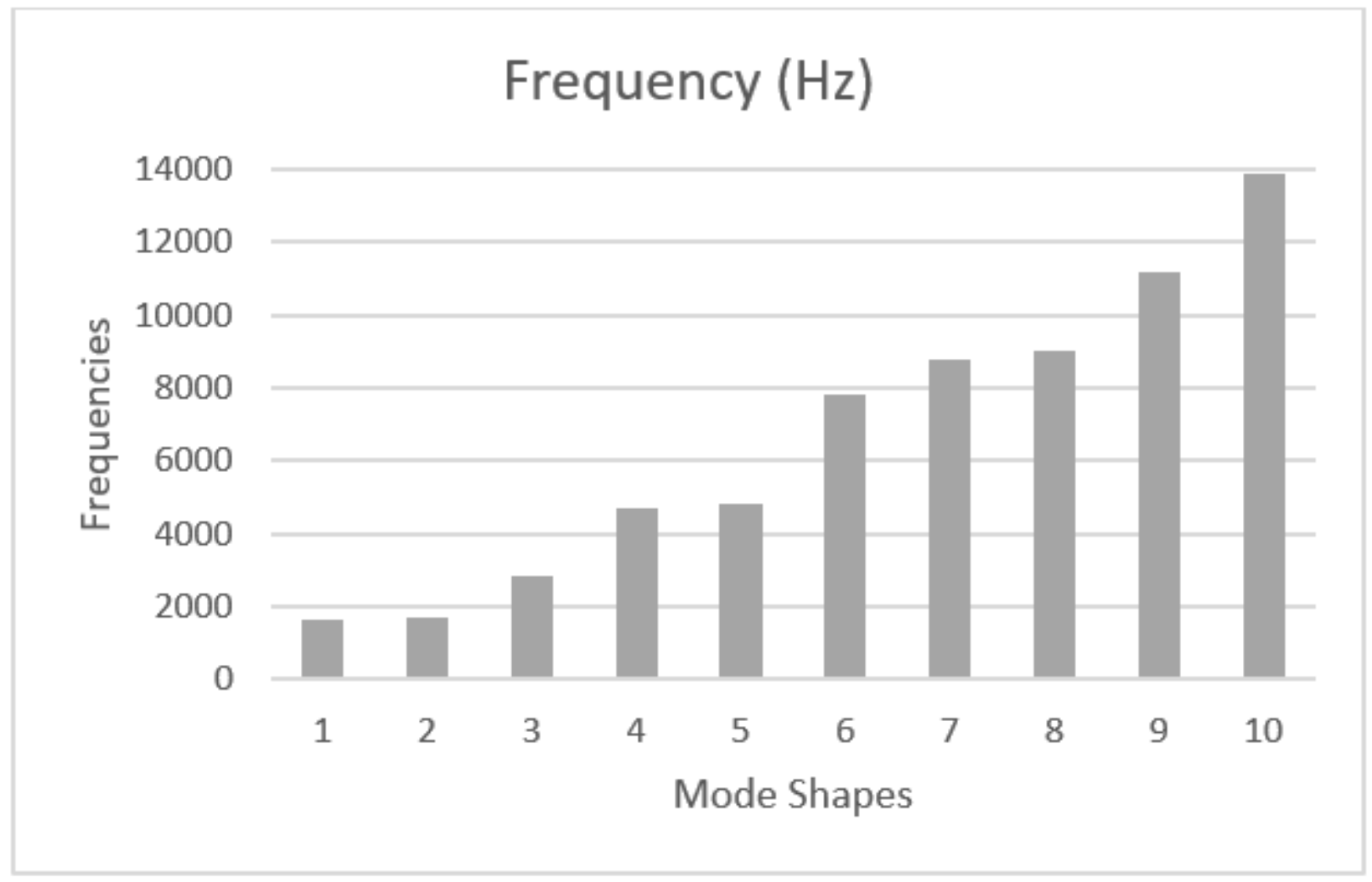

Figure 4 
graphical representation of frequency variation (SS-316)

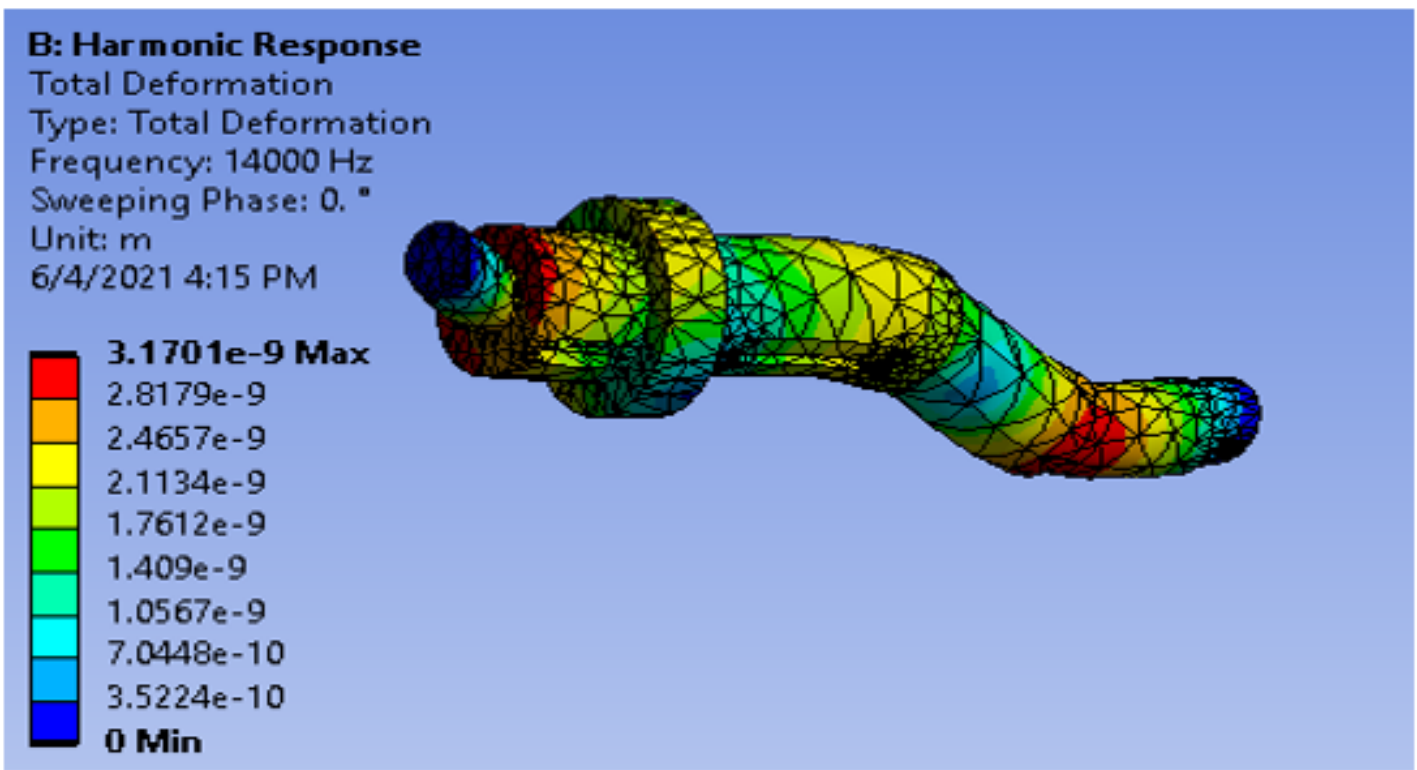

Figure 5

Total deformation (SS-316)

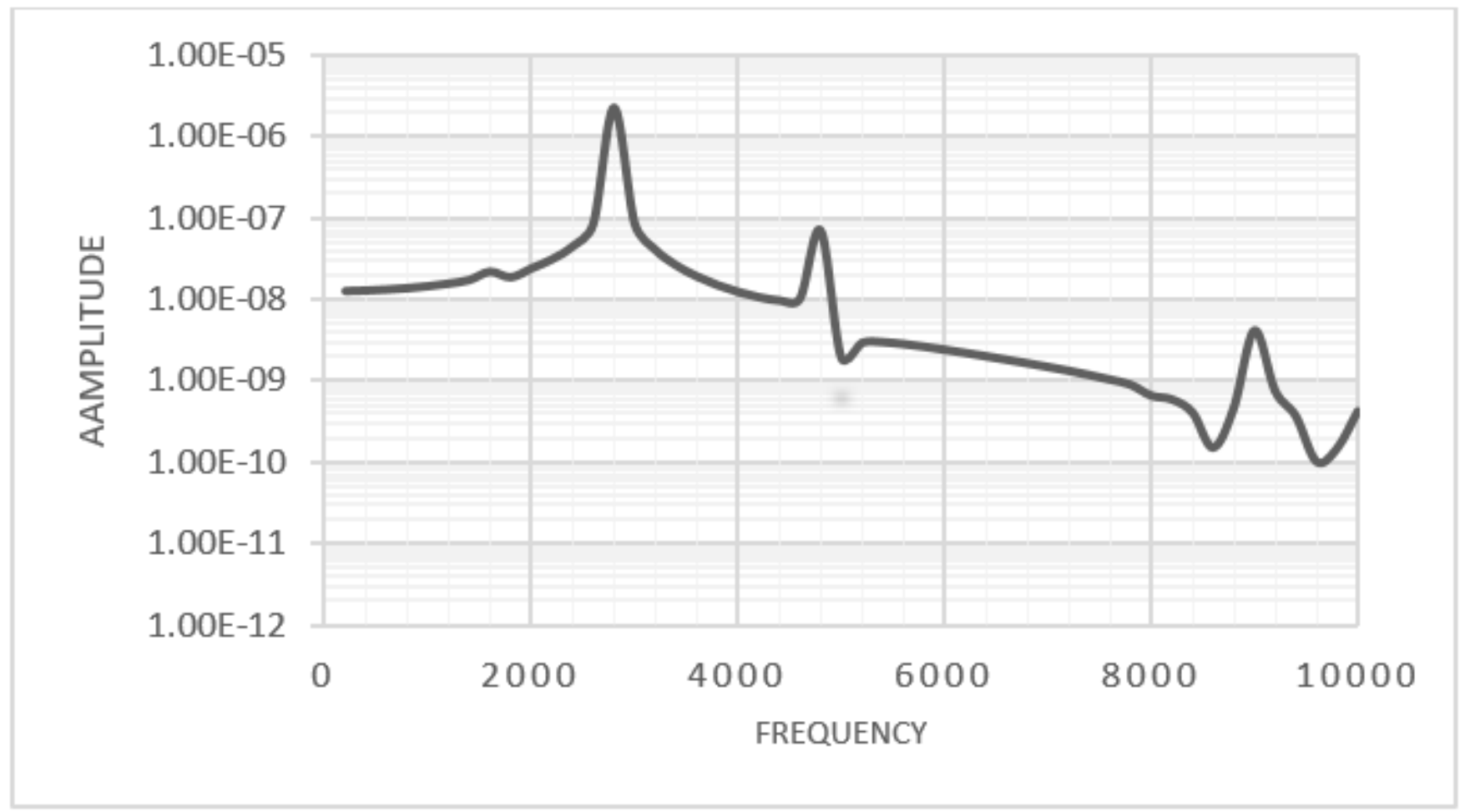

Figure 6

Frequency response (SS 316) 


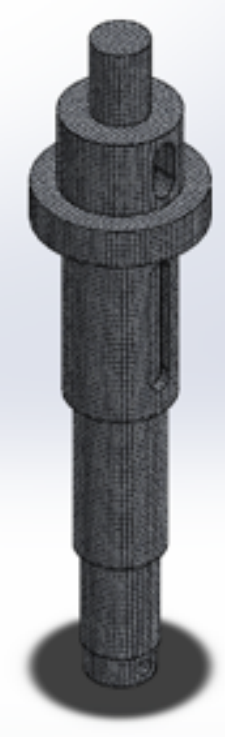

Figure 7

Engine Shaft (Carbon fiber applied)

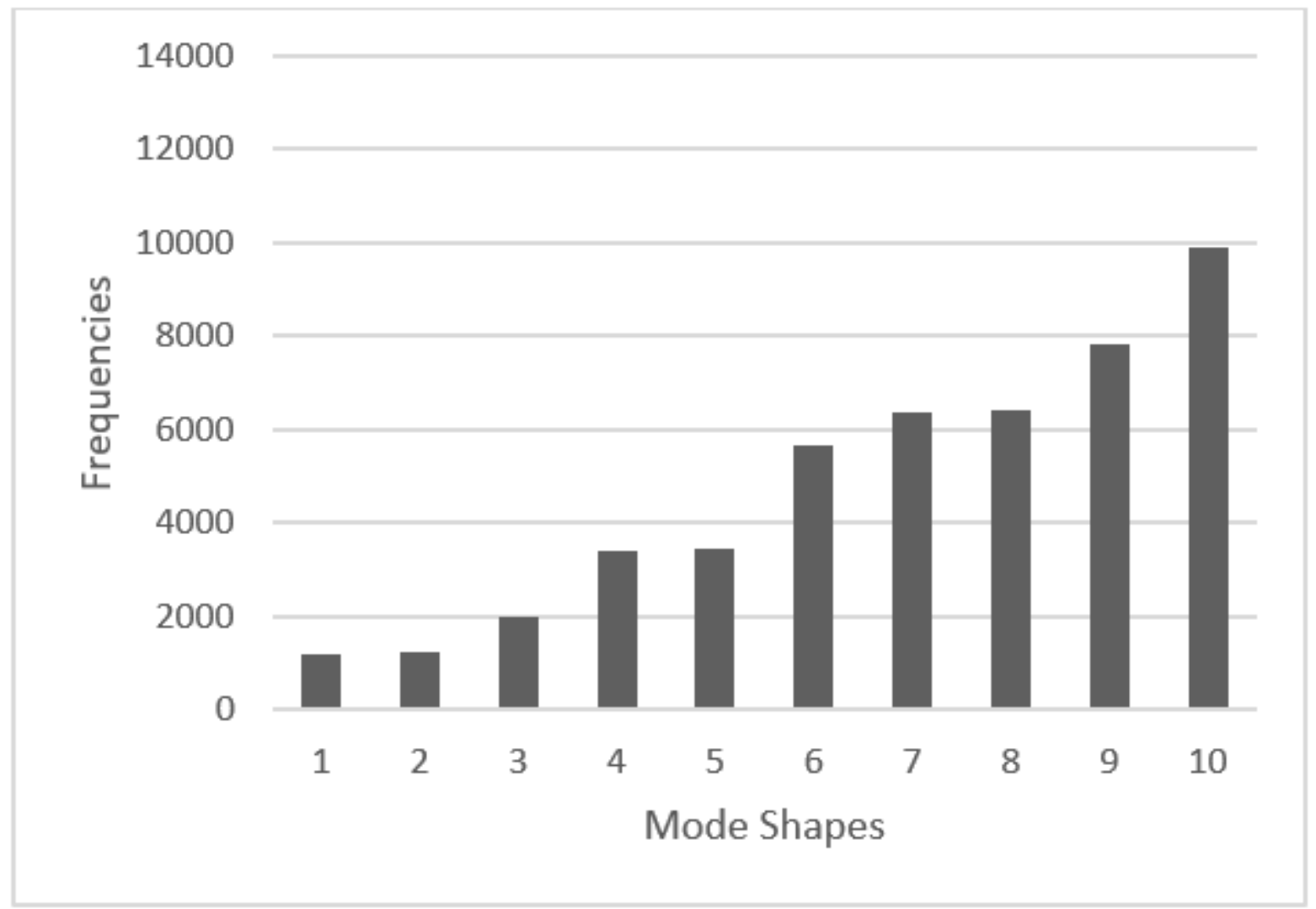

Figure 8

Variation of frequency (Carbon Fiber) 


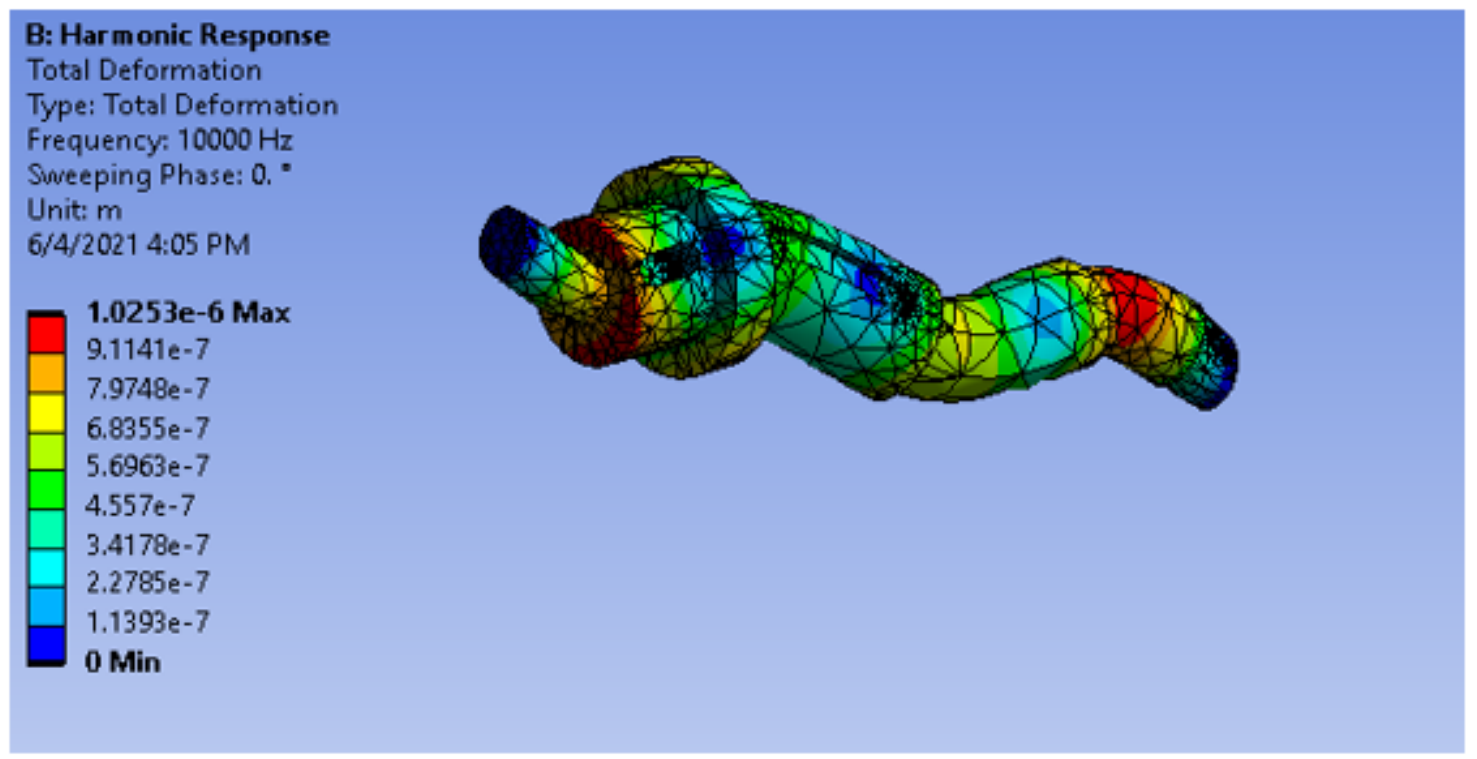

\section{Figure 9}

Total Deformation in engine shaft (Carbon fiber)

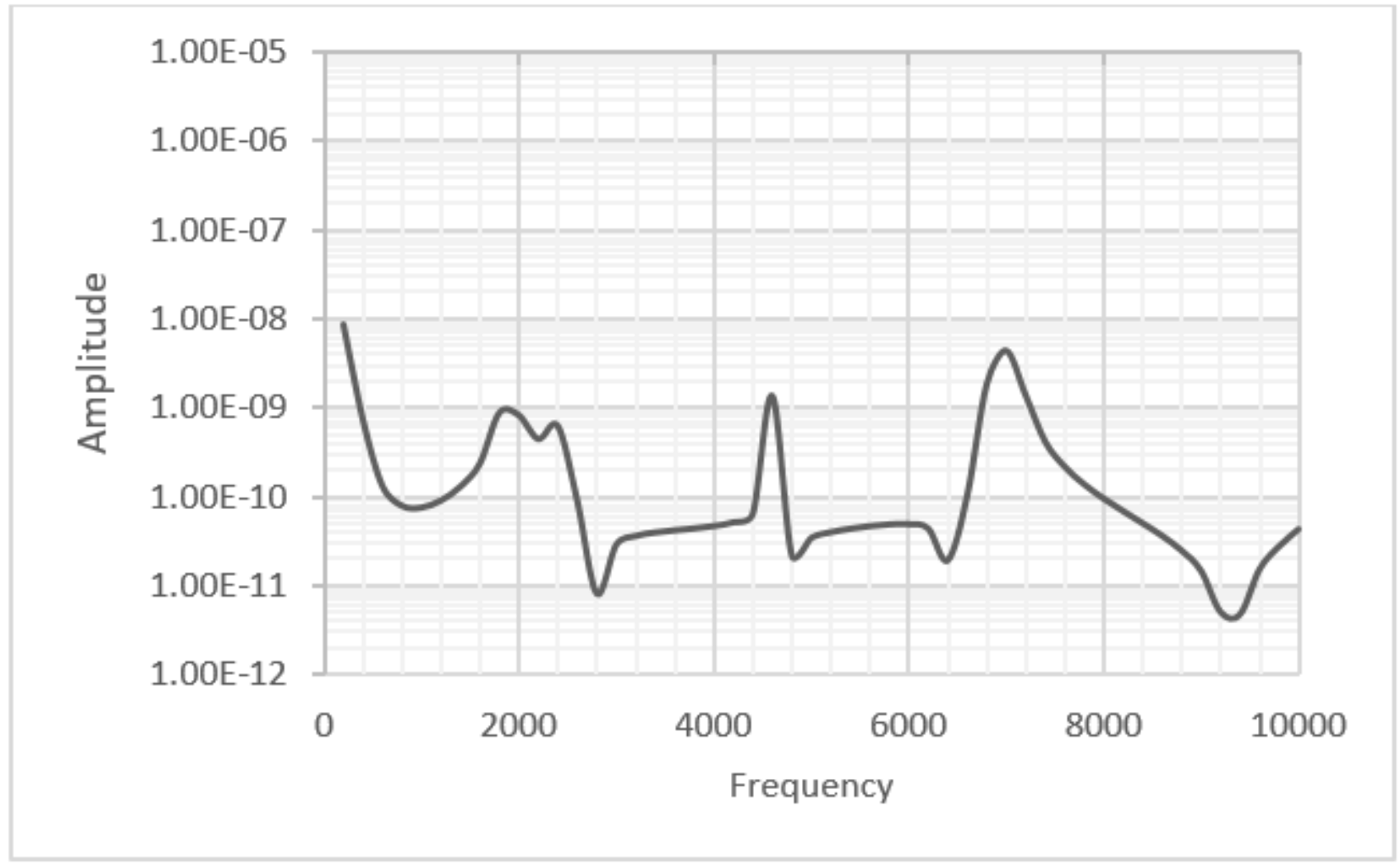

Figure 10

Frequency response (Carbon Fiber) 


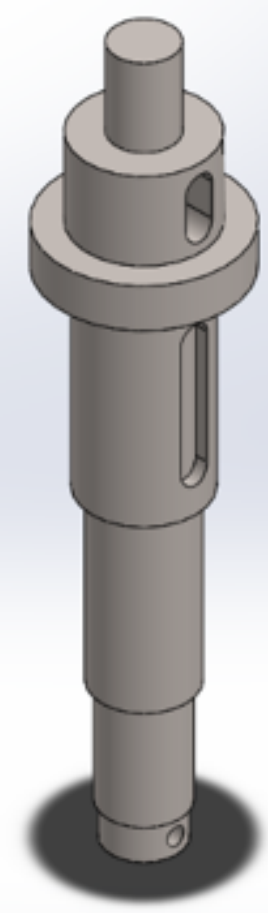

Figure 11

Engine Shaft (Ti-6Al-4V)

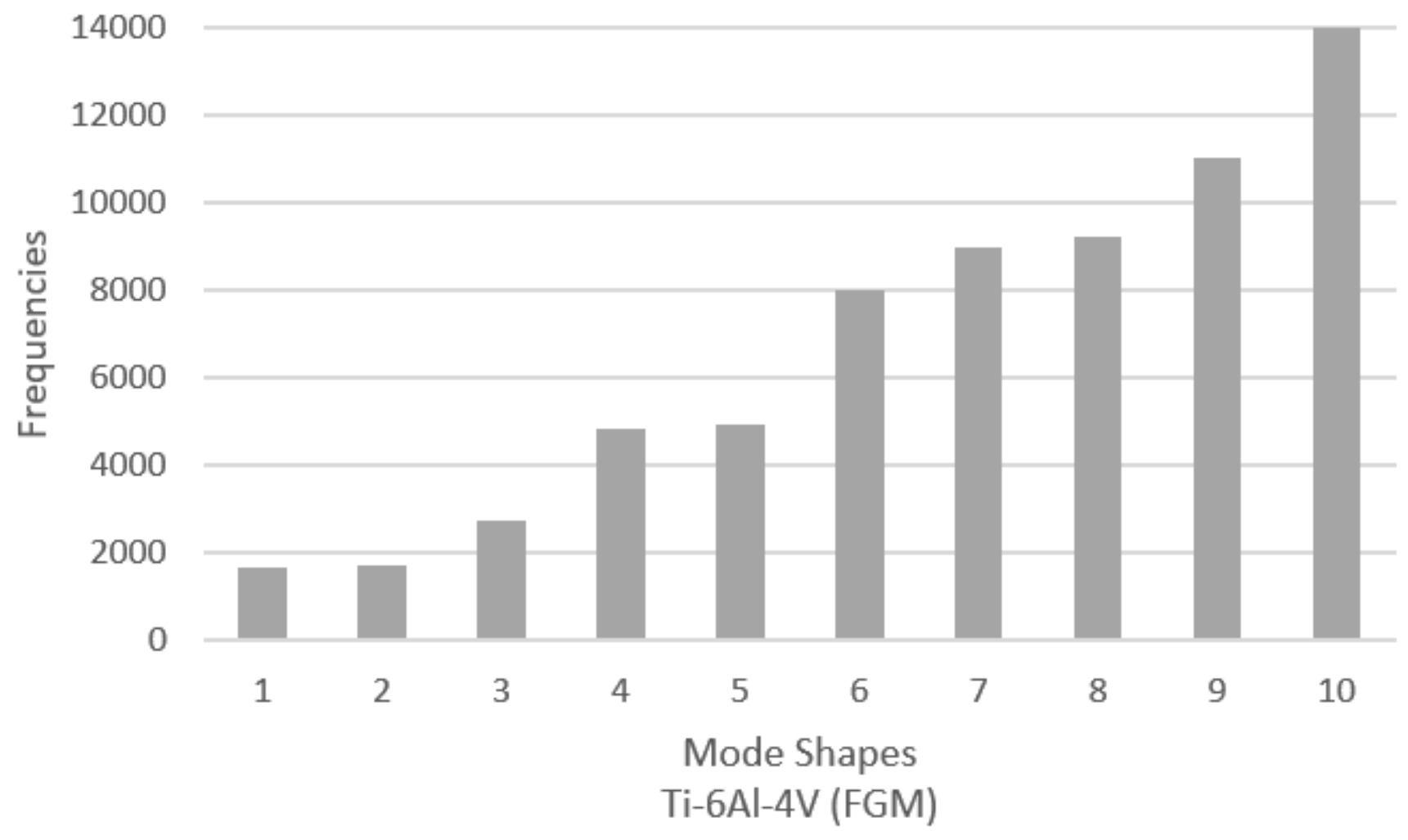


Figure 12

Frequency variation (Ti-6Al-4V)

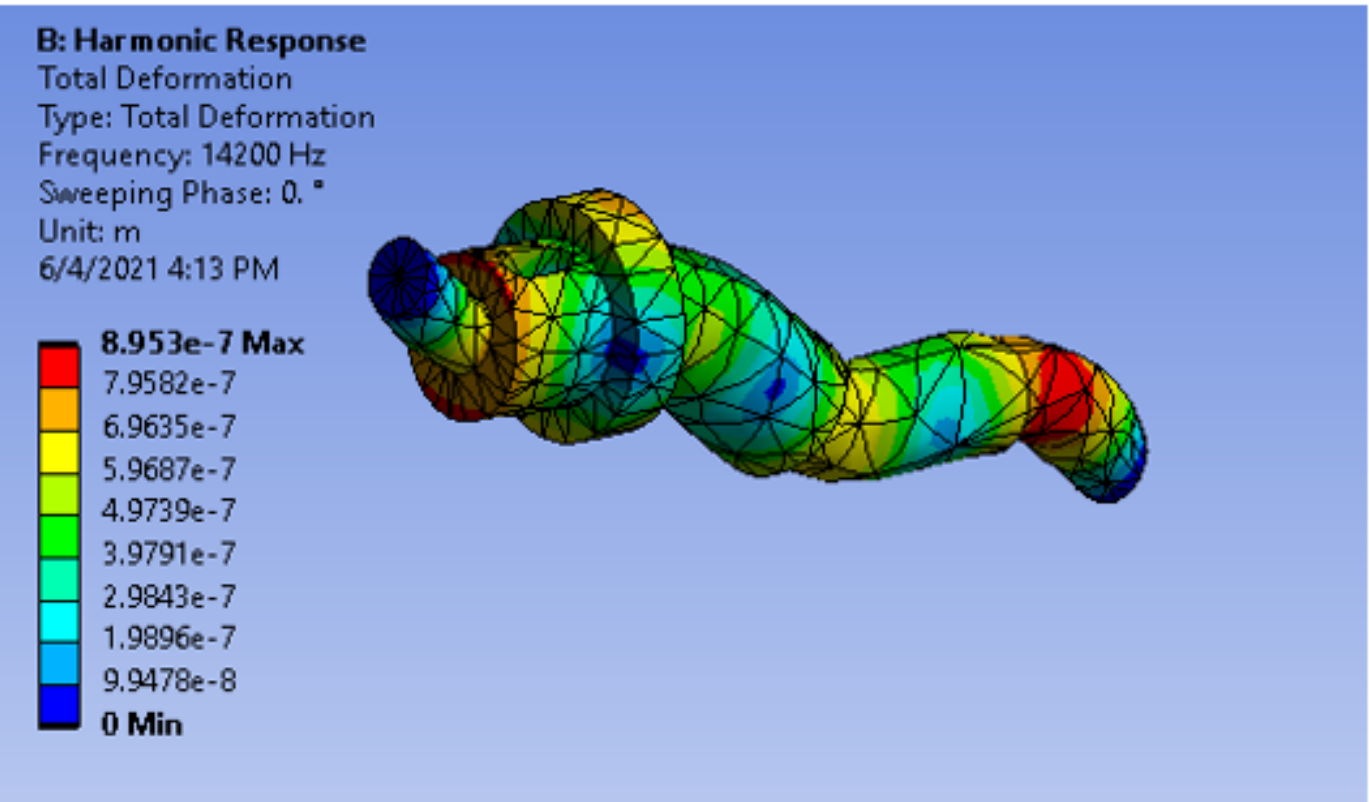

\section{Figure 13}

Total Deformation in engine shaft (Ti-6Al-4V)

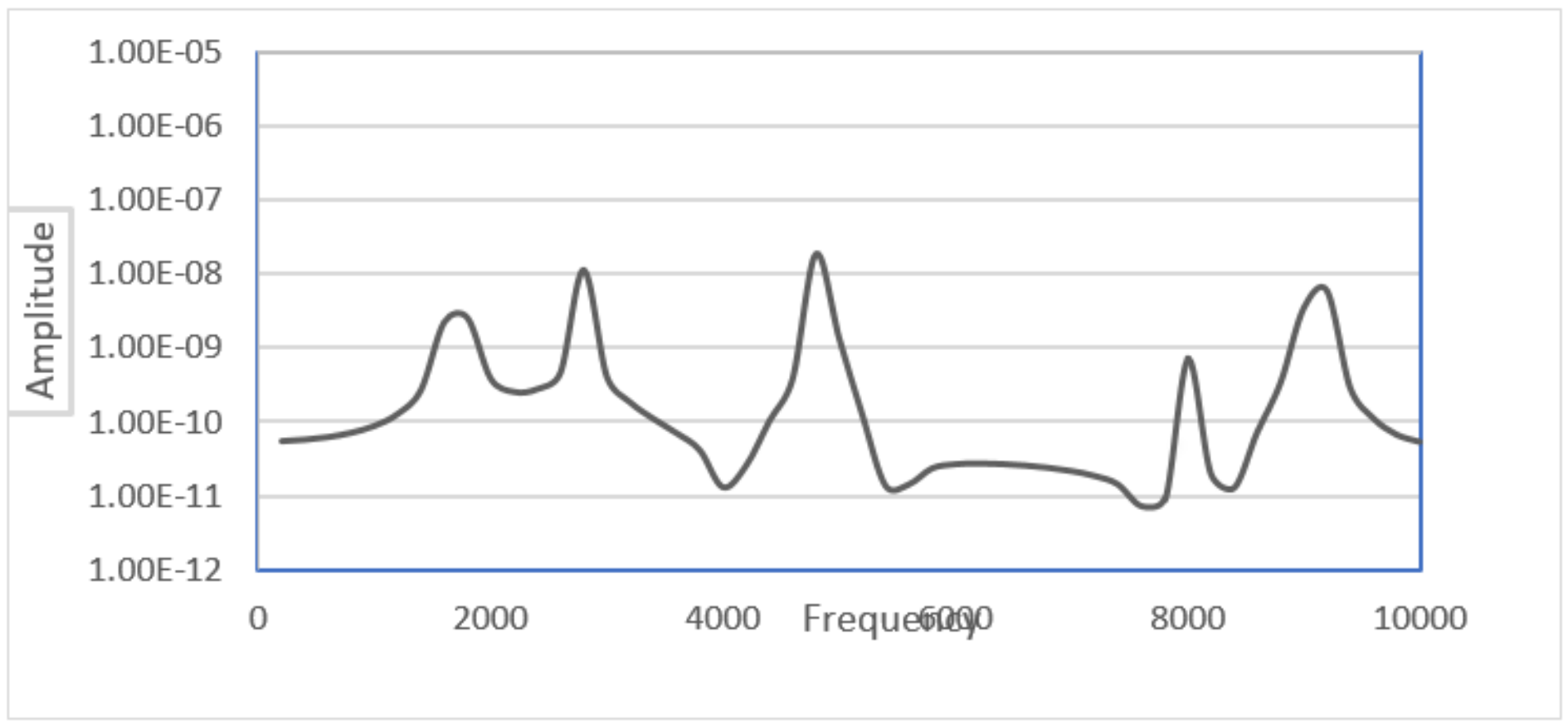

Figure 14

Frequency response (Ti-6Al-4V) 


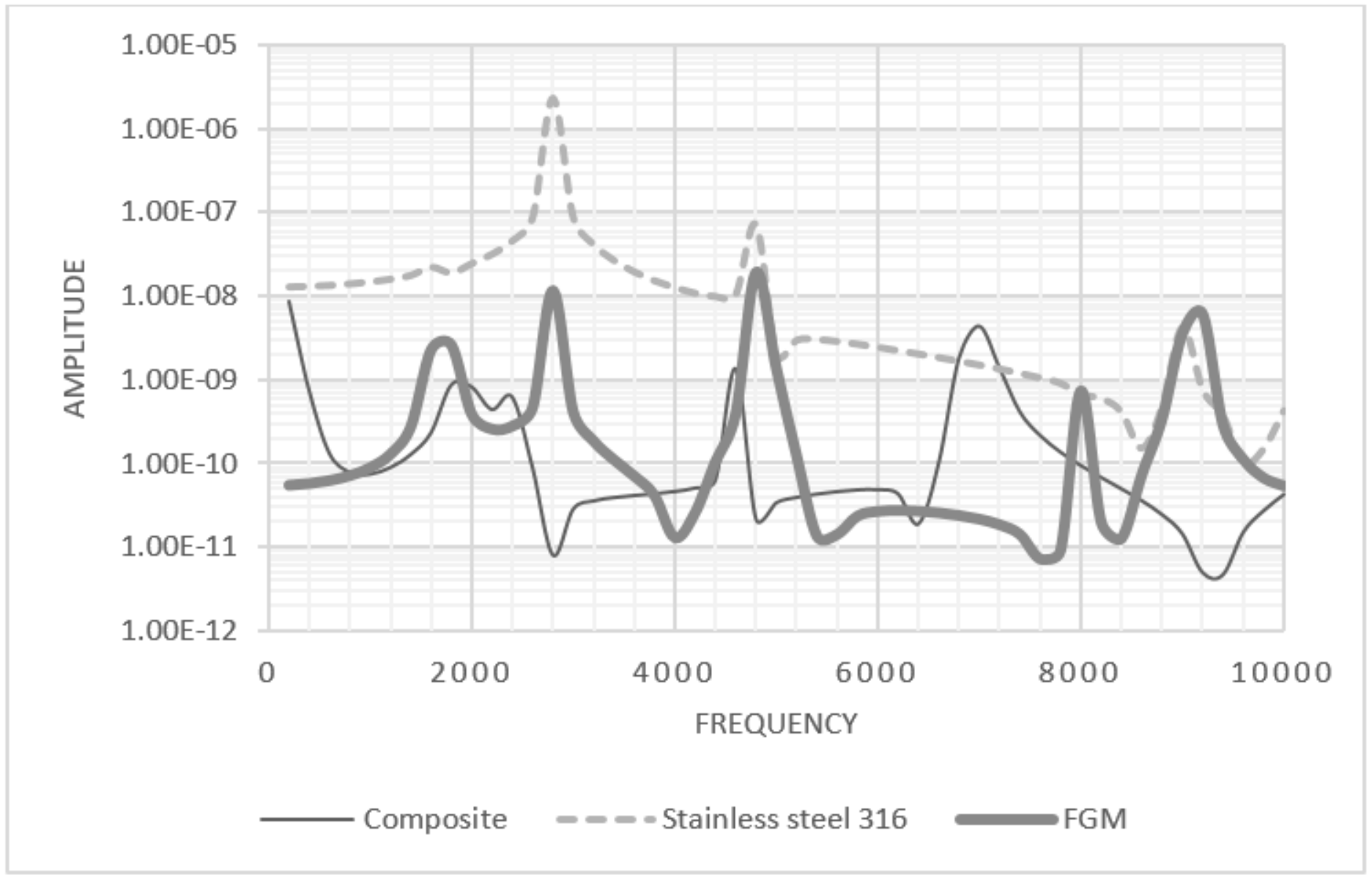

Figure 15

Comparison of frequency vs amplitude values for 3 shafts 


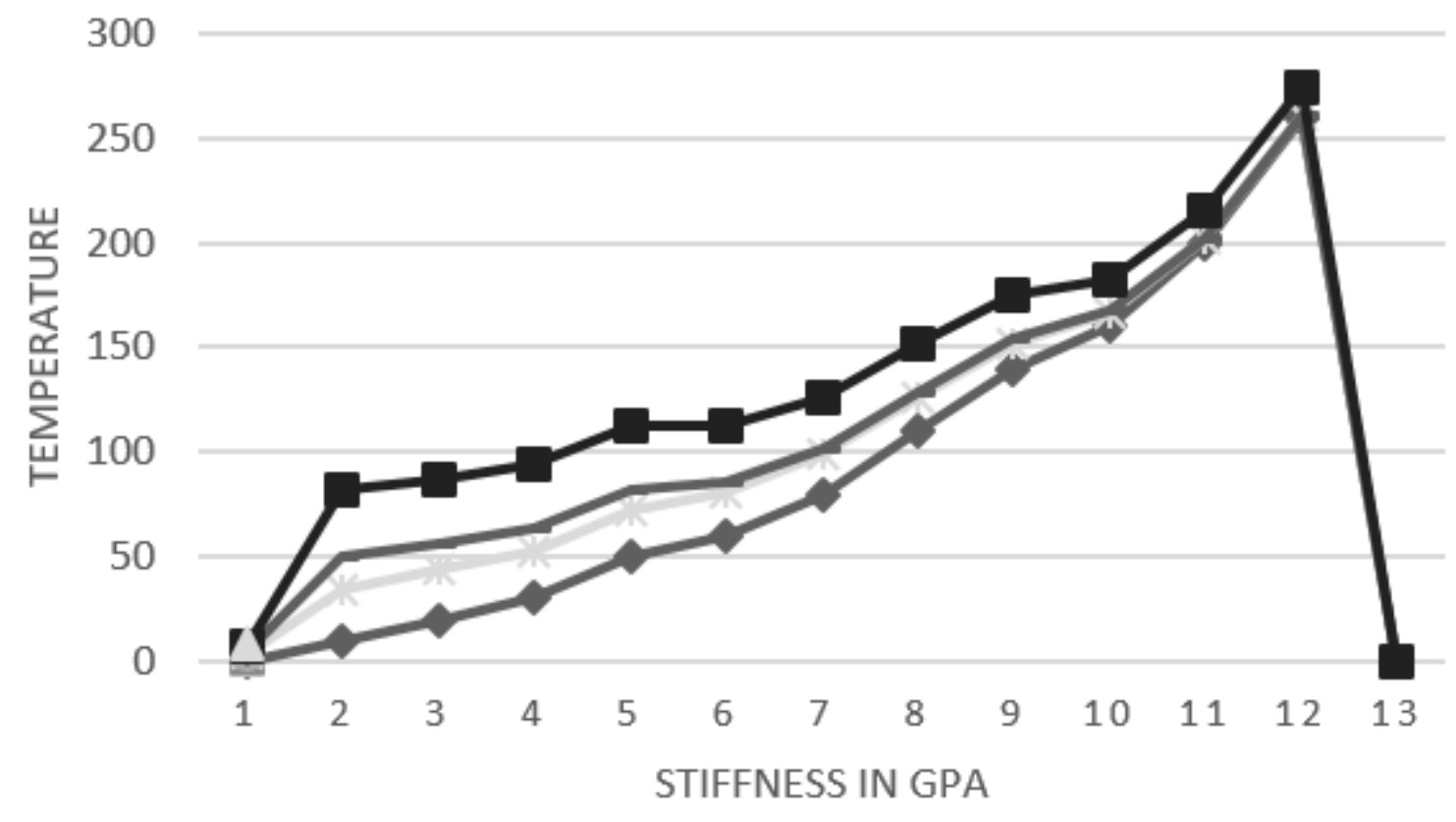

-Temperature Celsius $\quad-$ Carbon Fiber (GPa)

-Stainless Steel 316 (GPa) - Ti-4Al-6V (GPa)

Figure 16

Behavior of Stiffness with temperature

\section{Supplementary Files}

This is a list of supplementary files associated with this preprint. Click to download.

- GraphicalAbstract.png 